Schorn-Schütte, Luise, Tode, Sven, Debatten über die Legitimation von Herrschaft. Politische Sprachen in der Frühen Neuzeit

\title{
Claire Ravez
}

\section{OpenEdition}

1 Journals

Édition électronique

URL : http://journals.openedition.org/ifha/1703

DOI : 10.4000/ifha. 1703

ISSN : 2198-8943

Éditeur

IFRA - Institut franco-allemand (sciences historiques et sociales)

Référence électronique

Claire Ravez, "Schorn-Schütte, Luise, Tode, Sven, Debatten über die Legitimation von Herrschaft. Politische Sprachen in der Frühen Neuzeit », Revue de l'IFHA [En ligne], Date de recension, mis en ligne le 01 janvier 2008, consulté le 22 septembre 2020. URL : http://journals.openedition.org/ifha/1703 ; DOl : https://doi.org/10.4000/ifha.1703

Ce document a été généré automatiquement le 22 septembre 2020.

(C)IFHA 


\title{
Schorn-Schütte, Luise, Tode, Sven, Debatten über die Legitimation von Herrschaft. Politische Sprachen in der Frühen Neuzeit
}

\author{
Claire Ravez
}

1 L'avant-propos de l'ouvrage permet de comprendre l'itinéraire à emprunter pour lire avec profit ce recueil : il s'agit de celui de son éditrice et de son équipe, venus de l'histoire sociale des clergés catholique et protestant pour se tourner vers l'histoire de la communication politique. Le chapitre introductif permet alors de cibler l'objet qui doit constituer le lien entre des contributions sinon disparates : l'étude de situations propices à des débats théologico-politiques liés à la question de la légitimation des pouvoirs spirituel et/ou temporel doit ici être effectuée à l'aide des instruments conceptuels empruntés à Quentin Skinner et à l'École de Cambridge, c'est-à-dire en identifiant un vocabulaire politique propre à une époque et à un lieu, en le contextualisant et en en montrant l'évolution.

2 Les huit contributions (dont deux en anglais) insistent avec plus ou moins de bonheur sur ces éléments de contenu et de méthode. F. Hatje dissèque les sens du terme Freiheit à Leyde en 1579 à propos des modalités de désignation des pasteurs de la ville réformée ; A.N. Burnett insiste sur l'inféodation progressive du clergé bâlois dans les années 1540 ; R. Head analyse les discours et les images vétérotestamentaires liés à la légitimation de la participation active du clergé à la vie politique mouvementée dans le canton des Grisons pendant la première moitié du XVIIe s. Deux articles sont consacrés à la ville de Danzig : S. Tode analyse les enjeux du sermon comme instrument de communication dans des luttes à la fois confessionnelles et politiques entre luthériens et réformés à la fin du XVIe s., tandis que H.J. Müller montre la difficulté de s'entendre sur un principe de tolérance entre 1630 et 1650 . Trois articles plus isolés complètent le recueil. La justification théologique "chrétienne " par un conseil spécialisé d'une politique espagnole de la « raison d'État " sous Olivares, ainsi que ses limites (absence de 
certaines catégories de pensée, comme la coexistence confessionnelle) sont analysées par A. Wendland. La sécularisation du discours de légitimation politique est démontrée de façon exemplaire par T. Fuchs avec l'étude de l'historiographie dynastique pratiquée à Hanovre et à Cassel au XVIIe s. Les auteurs du recueil peuvent enfin trouver en l'Italien Vico un théoricien précoce de l'analyse du discours politique (N. Erny). Un index des noms de personnes et de lieux complète l'ouvrage.

3 Les études de cas abordées par ce recueil s'avèrent être très riches, ce qui rend au final presque agréable leur juxtaposition au nom d'étiquettes (langage politique, communication politique) qui n'en épuisent pas toujours la portée.

Claire Ravez (Lycée Fabert, Metz) 